\title{
Médiévales
}

Langues, Textes, Histoire

49 | automne 2005

La paroisse, genèse d'une forme territoriale

\section{Boris Bove, Dominer la ville : Prévôts des marchands et échevins parisiens de 1260 à 1350}

Paris, Comité des Travaux Historiques et Scientifiques, 2004, 750 p. (note de lecture traduite de l'anglais par Nicolas Weill-Parot)

John W. Baldwin

\section{OpenEdition}

Journals

Édition électronique

URL : https://journals.openedition.org/medievales/1210

DOI : $10.4000 /$ medievales. 1210

ISSN : $1777-5892$

Éditeur

Presses universitaires de Vincennes

Édition imprimée

Date de publication : 1 décembre 2005

Pagination : 174-176

ISBN : 2-84292-177-1

ISSN : 0751-2708

Référence électronique

John W. Baldwin, «Boris Bove, Dominer la ville : Prévôts des marchands et échevins parisiens de 7260 à

1350 », Médiévales [En ligne], 49 | automne 2005, mis en ligne le 12 mars 2007, consulté le 24 avril

2022. URL : http://journals.openedition.org/medievales/1210 ; DOI : https://doi.org/10.4000/

medievales. 1210

Ce document a été généré automatiquement le 24 avril 2022

Tous droits réservés 


\section{Boris Bove, Dominer la ville: Prévôts des marchands et échevins parisiens de 1260 à 1350}

Paris, Comité des Travaux Historiques et Scientifiques, 2004, 750 p. (note de lecture traduite de l'anglais par Nicolas Weill-Parot)

John W. Baldwin

1 Paris avant le $\mathrm{xv}^{\mathrm{e}}$ siècle présente à l'historien des défis inhabituels. Riche d'au moins 200000 habitants vers 1300, sa population avait été multipliée au moins par cinq durant le siècle écoulé au point d'en faire un véritable monstre démographique, la plus grande ville européenne au nord des Alpes. Cependant, les archives municipales, notariales ou personnelles, essentielles pour reconstruire l'histoire de ses habitants, font défaut. Par le passé, des historiens comme Raymond Cazelles et, plus récemment, Simone Roux, ont fait de leur mieux en traitant de façon éclectique les sources existantes, mais Boris Bove offre une approche plus structurée en se concentrant sur une petite partie de l'élite de cette population. En 1261, saint Louis établit un collège municipal, constitué du prévôt des marchands et de quatre échevins, qui fut aboli en 1383. Ce groupe a fourni quarante-sept noms de trente familles. En dépouillant toutes les archives, tant imprimées que manuscrites, en provenance des fonds ecclésiastiques, royaux et autres, B. Bove a élaboré une base de données de 8200 entrées pour éclairer les contours de ce groupe. Les registres d'imposition à partir de 1300 environ ont été particulièrement utiles. Bien que constituant une minorité infinitésimale de la population totale, ces échevins fournissent un fil rouge pour pénétrer au cœur d'une élite influente de 1260 à 1350.

2 Comme le roi n'avait pas autorisé sa capitale à former une commune et ne lui avait pas octroyé de franchises générales, mais qu'il avait seulement accordé des privilèges à des groupes spécifiques comme les marchands de l'eau, ce collège des échevins fut l'institution la plus proche d'un gouvernement municipal qui fût permise aux Parisiens, mais ses fonctions réelles ne furent pas clairement définies. Ses membres officiaient pour de courtes durées, accomplissaient d'autres tâches, et ne recevaient aucune 
rémunération directe. Le principal avantage (quoique indirect) était l'accès direct à la cour royale. À n'en pas douter, les échevins ont profité de la ferme de la prévôté de la ville lorsqu'ils assuraient cette responsabilité, mais cette rémunération fut réduite par les réformes de la prévôté associées au nom d'étienne Boileau, sur lequel Boris Bove livre un récit renouvelé.

Comme groupe d'élite, les échevins tiraient leur richesse de l'importation et de la redistribution des biens de luxe, en particulier les vêtements, au centre royal et ecclésiastique du royaume. Un quart de leurs membres étaient des marchands, un tiers s'occupaient de commerces ou d'artisanats divers; les autres n'ont pu être identifiés. Ils agissaient davantage comme hommes d'affaires que comme industriels et leurs services comprenaient des activités bancaires. Ils concentraient leurs propriétés principalement dans trois quartiers de Paris : aux alentours de l'entrée du Grand-Pont, sur la Cité, et aux alentours des Halles et de la place de Grève sur la rive droite, zones où leur lieu de travail et leur résidence étaient également établis. Leur demeure occupait modestement quelque $20 \mathrm{~m}^{2}$ au sol, mais elle était agrandie par l'adjonction et les nouvelles divisions de structures contiguës. À l'extérieur de Paris, ils possédaient rarement des propriétés au-delà d'un rayon de dix kilomètres (il s'agissait alors surtout de vignobles). Dans le «rôle » de la taille de 1328, leur richesse personnelle annuelle était très variable : de 300 à 16600 livres.

Boris Bove réussit particulièrement bien à poser des questions anthropologiques à ses données pour montrer comment les échevins ont cherché à créer une forte identité de groupe pour se distinguer du reste de la société parisienne. Après la noblesse, ils furent les premiers à adopter des patronymes familiaux et à les maintenir pour des générations. Par exemple, les noms de Arrode, Barbette, Boucel, Bourdon, Le Flament, Pisdoë et Popin apparaissent dès le règne de Philippe Auguste. Ils prirent des prénoms caractéristiques pour chacune des familles, et furent prompts à user de sceaux personnels et à créer des blasons héraldiques. Leurs relations avec les églises révèlent également des traits distinctifs. Tout en plaçant très souvent leurs filles dans les couvents éloignés de Chelles et Longchamp, ils ont limité leur patronage à des églises précises à l'intérieur de la ville où ils firent établir occasionnellement des chapelles familiales. Les Arrode préférèrent faire des dons à Saint-Martin-des-Champs, par exemple; et les Popin, à Saint-Germain-l'Auxerrois. Ils s'empressèrent d'entrer dans des confréries comme celles de Notre-Dame ou de Saint-Jacques. Boris Bove a retracé avec soin leurs fréquents intermariages qui leur apportèrent une solide cohésion sociale. Leurs relations avec la noblesse sont plus nuancées. Adoptant le noble divertissement de la fauconnerie, ils furent aussi sensibles aux genres aristocratiques de la littérature vernaculaire. Philippe Paon, par exemple, a composé de grands chants courtois pour leur plaisir, et Pierre Gencien a écrit Le Tournoiement des dames de Paris qui ne reflète pas seulement la pratique de la bourgeoisie parisienne consistant à parodier le principal sport aristocratique en y plaçant des participants de sexe féminin, mais illustre aussi une préoccupation pour le lignage familial allant jusqu'à la création de sa propre héraldique. (L'un des points particulièrement forts de l'étude de B. Bove est d'avoir replacé le poème de Gencien dans le milieu parisien). Cependant, les échevins se distinguaient clairement de l'aristocratie par leur toilette simple et ordinaire telle qu'elle apparaît dans l'effigie que l'on trouve sur leur tombe, et ils se sont rarement mariés dans des familles aristocratiques. Peut-être le trait le plus distinctif de l'élite échevine a-t-il été la distance à l'égard de l'Église parisienne. Même s'ils firent des legs pieux et s'ils placèrent leurs filles dans des couvents, ils n'eurent pas de haute ambition 
pour leurs fils dans la hiérarchie ecclésiastique. Au mieux, leurs fils devinrent des chanoines (rarement cependant à Notre-Dame), mais ils n'atteignirent jamais la prélature. Les échevins manifestèrent un manque d'intérêt marqué pour l'université de la rive gauche. Non seulement ils évitèrent $d$ 'y vivre, mais leurs fils ne se trouvent pas mentionnés dans les registres des nombreux collèges. Peu nombreux furent ceux qui obtinrent le grade de maître, et la plupart des familles évitèrent la culture latine savante des écoles et des universités.

Bien que constituant une infime minorité, les échevins, depuis leur origine, ont toujours été identifiés au statut de bourgeois à Paris, lequel a reçu une définition de plus en plus précise au cours du XIII ${ }^{\mathrm{e}}$ siècle jusqu'à ce que ses caractéristiques fussent devenues statutaires en 1287. À travers une documentation massive et une application rigoureuse des techniques prosopographiques, Boris Bove a solidement reconstruit la structure économique, sociale et culturelle du groupe échevinal. Comme élite, ce petit groupe a pesé lourdement par son influence sur les bourgeois contemporains, plus nombreux. Le travail de Boris Bove pourrait donc bien être l'approche la plus précise qui puisse être atteinte de la grande majorité des 200000 habitants de Paris au bas Moyen Âge. Son étude attentive offre une base solide pour des travaux ultérieurs et constitue une contribution majeure à l'histoire du Paris médiéval. 